\title{
The megalopa stage of Portunus spinimanus Latreille, 1819 and Portunus gibbesii (Stimpson, 1859) (Decapoda, Brachyura, Portunidae) from the southeastern Atlantic coast of the United States
}

\author{
MARIA LUCIA NEGREIROS-FRANSOZO ${ }^{1,3}$, NADIA MEYERS $^{2}$, VÍVIAN FRANSOZO ${ }^{1} \&$ \\ SUSAN THORTON-DE VICTOR ${ }^{2}$ \\ ${ }^{I}$ Nebecc (Crustacean Biology, Ecology and Culture Study Group), Departamento de Zoologia, IBB, Universidade Estadual Paulista, \\ 18618-000 Botucatu, SP, Brazil \\ ${ }^{2}$ Southeastern Regional Taxonomic Center, Marine Resources Research Institute, PO Box 12559, Charleston, SC, 29422-2559 U.S.A. \\ ${ }^{3}$ Corresponding author. E-mail: mlnf@ibb.unesp.br
}

\begin{abstract}
The identification of megalopae from plankton samples is difficult, because this larval stage is the least well known among crab larvae, unknown in some species and poorly described in others. Wild megalopa specimens of some swimming crabs (family Portunidae Rafinesque, 1815) were captured alive from neuston samples obtained during summer surveys near the coast of Charleston, South Carolina (U.S.A). For identification purposes, larvae were reared to the 8th juvenile instar. After reaching the 5th juvenile instar, the juvenile crabs exhibited morphological features suitable for identification to the species level. The specimens belonged to two species of Portunidae, Portunus spinimanus Latreille, 1819 and P. gibbesii (Stimpson, 1859). Their megalopae were described in detail and compared to other portunid megalopae known from the southeastern Atlantic coast of the U.S.A. Species-specific characters of portunid megalopae are the number of carpal spines on the chelipeds, the relative size of the sternal spines ( 7 th sternite), the number of antennal flagellum segments, and the setation of mouthparts.
\end{abstract}

Key words: Portunus, megalopa, neuston, Decapoda, Brachyura, U.S. southern Atlantic coast

\section{Introduction}

An adequate knowledge of the zooplankton, including the larval forms, is of great importance for understanding the vital link between primary producers and consumers (Wickstead, 1976). However, larvae of most species remain unknown. Among brachyuran crabs alone, which represent about half of the estimated species of Decapoda, most of their larvae are still not described (Pohle et al., 1999).

While the identification of wild-caught megalopae is problematic because of the lack of general knowledge, there are, nevertheless, some morphological features that characterize members of particular families (Pohle et al., 1999). The megalopae of Portunidae can be distinguished from other brachyurans by the following characters: an acute rostrum projecting almost horizontally; the dactyl of the last pereopods paddle-like as in the adult crab; and, in some species, the larvae bear spine-like projections on the sternum. Such features can be observed in species that belong to the following genera for which melagopae have been described: Portunus Weber, 1795 studied by Kurata (1975); Thalamita Latreille, 1829, by Fielder and Greenwood (1979); Charybdis De Haan, 1833, by Fielder et al. (1984); Arenaeus Dana, 1851, by Stuck and Truesdale (1988); and Callinectes Stimpson, 1860, by Costlow and Bookhout (1959). In the genera Ovalipes Rathbun, 1898 described by Costlow and Bookhout (1966), the spine-like projections on the sternum were not present; and in Liocarcinus Stimpson, 1870 these were not illustrated or described by Kim and Hong (1999). 